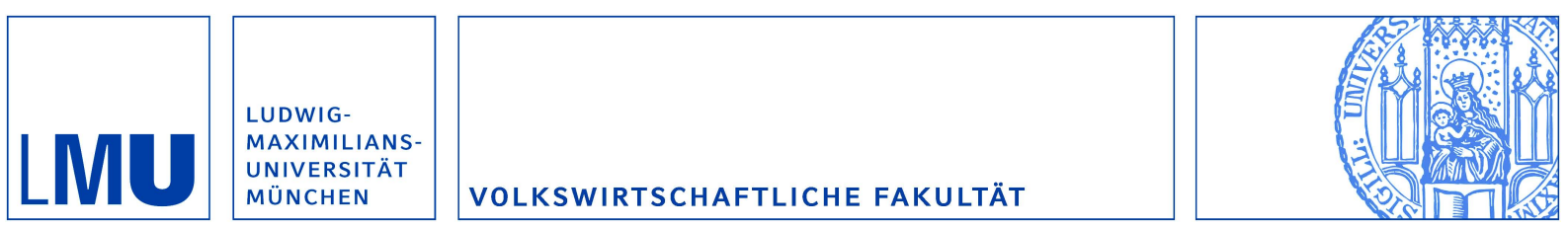

Ludwig, Sandra; Wichardt, Philip C. und Wickhorst, Hanke:

On the Positive Effects of Overcon fident

Self-Perception in Teams

Munich Discussion Paper No. 2011-11

Department of Economics

University of Munich

Volkswirtschaftliche Fakultät

Ludwig-Maximilians-Universitäł München

Online at https://doi.org/10.5282/ubm/epub. 12246 


\title{
On the Positive Effects of Overconfident Self-Perception in Teams*
}

\author{
Sandra Ludwig ${ }^{\dagger}$ \\ Dept. of Economics, LMU Munich \\ Philipp C. Wichardt \\ Dept. of Economics, University of Bonn \\ Hanke Wickhorst ${ }^{\S}$ \\ Münster School of Business and Economics
}

This Version: April 29, 2011

\begin{abstract}
In this paper, we study the individual payoff effects of overconfident self-perception in teams. In particular, we demonstrate that the welfare of an overconfident agent in a team of one rational and one overconfident agent or a team of two overconfident agents can be higher than that of the members of a team of two rational agents. This result holds irrespective of the assumption about the agents' awareness of their colleague's bias. Moreover, we show that an overconfident agent is always better of when he is unaware of a potential bias of his colleague.
\end{abstract}

Keywords: Overconfidence, Team Production.

JEL classification: D21, D62, L23.

*Acknowledgments: We are grateful to Martin Kocher and an anonymous referee for helpful comments and suggestions. Financial support of the German Research Foundation (DFG), through SFB/TR 15 at the University of Bonn, is gratefully acknowledged. The usual disclaimer applies.

†Seminar for Economic Theory, LMU Munich, Ludwigstr. 28 (Rgb.), D-80539 Munich, Germany; e-mail: sandra.ludwig@lrz.uni-muenchen.de

$\ddagger$ Economic Theory 3, University of Bonn, Adenauerallee 24-42, D-53113 Bonn, Germany; e-mail: philipp.wichardt@uni-bonn.de.

${ }^{\S}$ Corresponding author. Institute for Organisational Economics, Center for Interdisciplinary Economics, University of Münster, Scharnhorststr. 100, D-48151 Münster, Germany; e-mail: hanke.wickhorst@uni-muenster.de. 


\section{Introduction}

Considerable evidence from psychology suggests that individuals tend to overestimate their own skills (e.g. Larwood and Whittaker, 1977; Weinstein, 1980; Svenson, 1981; or Taylor and Brown, 1988; for recent reviews see Alicke and Govorun, 2005; Moore and Healy, 2008; or Skata, 2008). ${ }^{1}$ Given the apparent relevance of the phenomenon for many economic contexts, the effects of overconfidence have also received considerable attention in the economic literature in recent years. For example, Heaton (2002) and Malmendier and Tate $(2005,2008)$ find that managers who overestimate their ability undertake more welfare reducing mergers and investments. Moreover, according to Kyle and Wang (1997) and Hirshleifer and Luo (2001) overconfident fundmanagers are promoted with higher probability due to the higher profits they gain, while Grinblatt and Keloharju (2009) find that overconfidence leads to excessive trading of stock-traders. Despite the differences in the desirability of eventual outcomes, one general pattern seems to be that individuals who overestimate their own skill tend to work harder than individuals assessing their ability correctly (see also Felson, 1984; Locke and Latham, 1990; Heath et al., 1999; and more recently Zhang and Fishbach, 2010).

In the present paper, we take up the discussion about the effects of overconfidence and analyse a general model of a teamwork situation with effort complementarities. Different from the previous literature on the effects of overconfidence (e.g. Hvide, 2002; de la Rosa, 2007; Gervais and Goldstein, 2007; or Santos-Pinto, 2008), ${ }^{2}$, however, we do not only consider the poten-

\footnotetext{
${ }^{1}$ Note that the notion of overconfidence in general is not uncontested (e.g. Gigerenzer et al., 1991, and Juslin, 1994; replies by Griffin and Tversky, 1992, and Kahnemann and Tversky, 1996). Recent meta-studies by Koehler et al. (2002) and Brenner and Griffin (2004), however, describe overconfidence as a prevalent phenomenon.

${ }^{2}$ Hvide (2002) considers a case where the agent can actually choose the beliefs about his ability and shows that biased beliefs can be beneficial to the agent as they may improve his outside option while they are detrimental for the firm. De la Rosa (2007) analyses welfare effects of overconfidence in a setting in which firms compete for an overconfident and risk-averse agent; he finds that the agent benefits when his bias is moderate. Along the same lines, Gervais and Goldstein (2007) analyse a model of team production with effort complementarities and show how overconfidence reduces free-riding and might increase both a rational as well as an overconfident agent's welfare and give rise to a Paretoimprovement. Focusing on the principal, Santos-Pinto (2008) considers a situation where
} 
tial advantage overconfident agents may have in a team of mainly rational agents but also ask how individual payoffs are affected if overconfidence becomes more common, i.e. affects both team members, and develops in a way that is "individually optimal" in terms of the agents' awareness of the biases of others.

As the subsequent analysis shows, overconfidence may not only enhance the team productivity (due to increased efforts) but also the welfare of the biased agent himself, and this holds in a team of one overconfident and one rational agent as well as in a team of two overconfident agents. Moreover, the result is particularly strong if the considered agent's overconfidence is combined with unawareness of other people's biases (despite the fact that being aware of the other's bias is closer to the true state of the world). Thus, our results not only provide a potential rationale for the wide dissemination of overconfidence suggested by the studies cited above. They also provide a potential rationale for the recent empirical finding that overconfident people tend to be unaware of the biases of others (Ludwig and Nafziger, 2011).

The intuition behind these results is rather straightforward: Due to the effects of synergy, overconfidence of another team member increases the optimal effort level for any agent who is aware of this bias. However, if an agent is overconfident himself, his effort level is already above the individual optimum - because of his own bias which he is unaware of. Awareness of a colleague's bias, then, leads to a further (suboptimal) increase in his effort. By contrast, lack of such awareness keeps the expectation about the colleague's effort and, hence, the agent's extra effort, which he exerts in order to exploit effort complementarities, low. In combination with the increase in the agent's effort due to his own overconfidence, the agent's effort choice gets closer to the overall individual optimum than if he were aware of the other's bias. In a sense, all necessary upward-adjustments in the agent's effort (in order to exploit the synergies from the colleague's overconfidence) are already accounted for in the agent's effort choice - although for a different reason,

the principal can condition wages on each agent's output; he shows that overconfidence is beneficial for the principal if effort is observable while it need not be in the presence of moral hazard. 
namely the agent's own overconfidence (which he is unaware of). And this intuition essentially covers both cases, i.e. a team with one biased and one rational agent and a team with two biased agents.

The rest of the paper is structured as follows: Section 2 presents our baseline model of a teamwork situation with effort complementarities. Section 3 introduces overconfidence in a team of one overconfident and one rational agent. Moving to teams of two overconfident agents, Section 4 consider the effects of changes in the information structure in such instances. Section 5, then, compares teams of two overconfident agents with teams of two rational agents and summarises the main points of the analysis. Section 6 concludes.

\section{The Baseline Model}

Consider an all-equity firm that is owned by risk neutral shareholders. The firm's output generates from a single one-period project which is carried out by two risk neutral agents, $i=1,2$, where teamwork is implemented in order to create positive externalities. ${ }^{3}$ The value of the project is the value of its expected cash flow which depends on the agents' efforts, $e_{i}$, and their abilities, $a_{i}$; for the sake of argument, we assume $a_{1}=a_{2}=a^{4}$ Moreover, we assume that agent $i$ 's expected return from the project, denoted by $R^{i}\left(e_{i}, e_{-i}\right)$, is increasing in effort and ability and that the marginal return to effort is increasing in ability, i.e. $d^{2} R^{i} / d e_{i} d a_{i}>0$. The agents' cost of effort is denoted by $c\left(e_{i}\right)$ with $c(0)=0, c^{\prime}>0$ and $c^{\prime \prime}>0$. Finally, in order to make the subsequent discussion meaningful, we assume that the agents'

\footnotetext{
${ }^{3}$ On positive externalities through teamwork see e.g. Alchian and Demsetz (1972), Grossmann and Hart (1986), Alchian and Woodward (1987), Aghion and Tirole (1994), Jensen and Meckling (1995), or Holmström and Roberts (1998).

${ }^{4}$ Note that assuming equal ability is not restrictive for the present argument. In particular, the focus of the analysis is on the individual effects of overconfidence and information about such biases of other team members. And, as such, the discussion is essentially confined to the consequences of changes in these parameters for one of the two agents. In fact, actual ability is not explicitly accounted for as we will treat it as fixed throughout the analysis.
} 
efforts are strategic complements, i.e.. ${ }^{5}$

$$
\frac{d e_{i}}{d e_{-i}}>0
$$

Under the above assumptions, the maximisation problem of agent $i$ can be written as follows:

$$
\max _{e_{i}} R^{i}\left(e_{i}, e_{-i}\right)-c\left(e_{i}\right),
$$

with first-order condition (FOC):

$$
R_{e_{i}}^{i}\left(e_{i}, e_{-i}\right)=c^{\prime}\left(e_{i}\right)
$$

Moreover, the corresponding second-order condition (SOC) is satisfied if:

$$
R_{e_{i} e_{i}}^{i}\left(e_{i}, e_{-i}\right)-c^{\prime \prime}\left(e_{i}\right)<0
$$

which we assume to hold in the following.

Substituting the corresponding equilibrium efforts, denoted by $e_{i}^{*}$ with $i=1,2$, into the agents' payoff functions, we obtain the following general expression for the agents' equilibrium payoffs in the case without overconfidence:

$$
U_{i}\left(e_{i}^{*}, e_{-i}^{*}\right)=R^{i}\left(e_{i}^{*}, e_{-i}^{*}\right)-c\left(e_{i}^{*}\right)
$$

These payoffs will serve as our benchmark for later comparisons.

\section{Overconfidence}

In order to analyse the effects of overconfidence, we first consider a team in which one agent, say agent 2 , is overconfident while the other agent, agent 1 , is rational and aware of agent 2's bias. In particular, we assume that agent 2 overrates his own skill by $b_{2}>0$, i.e. his perceived ability is $a_{2}^{\prime}:=a+b_{2}{ }^{6}$

\footnotetext{
${ }^{5}$ Efforts being strategic complements corresponds to the slope of the best reply being positive, which is here $\frac{d e_{i}}{d e_{-i}}=\frac{R_{e_{i} e_{-i}}\left(e_{i}, e_{-i}\right)}{c^{\prime \prime}\left(e_{i}\right)}>0$.

${ }^{6}$ Note that we consider overconfidence in the form of overestimation of one's absolute ability (see, e.g., Gervais and Goldstein, 2007, for a similar approach). In general, overconfidence can arise in other forms like overestimation of relative abilities ("better-than-
} 
Moreover, we assume that agent 2 is not aware of his own bias so that agent 2's maximisation problem can be written as follows: ${ }^{7}$

$$
\max _{e_{2}} \widetilde{R}^{2}\left(e_{1}, e_{2} \mid b_{2}\right)-c\left(e_{2}\right)
$$

where $\widetilde{R}^{2}\left(e_{1}, e_{2} \mid b_{2}\right)$ denotes the expected return to the project as (wrongly) perceived by the biased agent 2, i.e. $\widetilde{R}^{2}\left(e_{1}, e_{2} \mid b_{2}\right)=R^{2}\left(e_{1}, e_{2} \mid a_{1}=a, a_{2}=\right.$ $\left.a+b_{2}\right)$. The resulting FOC is given by:

$$
\widetilde{R}_{e_{2}}^{2}\left(e_{1}, e_{2} \mid b_{2}\right)=c^{\prime}\left(e_{2}\right)
$$

with SOC:

$$
\widetilde{R}_{e_{2} e_{2}}^{2}\left(e_{1}, e_{2} \mid b_{2}\right)-c^{\prime \prime}\left(e_{2}\right)<0
$$

Note that, compared to a situation without overconfidence $\left(b_{2}=0\right)$ the effort of agent 2 increases, for a given effort level of agent 1, as the marginal return to effort of agent 2 is increasing in $b_{2}$ :

$$
\frac{d e_{2}}{d b_{2}}=-\frac{\widetilde{R}_{e_{2} b_{2}}^{2}\left(e_{1}, e_{2} \mid b_{2}\right)}{\widetilde{R}_{e_{2} e_{2}}^{2}\left(e_{1}, e_{2} \mid b_{2}\right)-c^{\prime \prime}\left(e_{2}\right)}>0
$$

recall that, by construction, the nominator of (9) is positive - due to the assumed positive effect of the agents' ability on marginal productivity - and the denominator is negative which follows from the SOC (see (4) and (8)).

The maximisation problem of agent 1 , in turn, is the same as described in the baseline model of a fully rational team except that agent 1 now takes the bias $b_{2}$ of agent 2 into account; i.e. agent 1 knows that agent 2's effort changes due to his overconfidence and accounts for this. Thus, agent 1 knows that agent 2 is biased and while agent 2 knows this, he disagrees with agent 1, i.e. the agents agree to disagree as, for example, in Morris (1996) and Squintani (2006). ${ }^{8}$

average effect", e.g. Svenson, 1981); or personal control ("illusion of control", e.g. Langer, 1975); as well as unrealistic optimism about the future (e.g. Weinstein, 1989).

${ }^{7}$ Note that overconfidence would have no behavioural effect if agents were aware of their bias (and otherwise rational, i.e. expected utility maximisers).

${ }^{8}$ Note that beliefs in this type of argument are used essentially to motivate equilib- 
Denoting the resulting equilibrium efforts with $\hat{e}_{1}$ and $\hat{e}_{2}$, the agents' individual equilibrium payoffs based on actual and not perceived abilities (and thus actual rewards) are:

$$
U_{i}\left(\hat{e}_{i}, \hat{e}_{-i}\right)=R^{i}\left(\hat{e}_{i}, \hat{e}_{-i}\right)-c\left(\hat{e}_{i}\right)
$$

The qualitative effect of changes in agent 2's perceived ability on agent 1's expected payoff, then, can be summarised as follows; for any $b_{2} \in[0, \bar{b})$, where $\bar{b}$ denotes some upper bound on agent 2's bias (possibly $\bar{b}=\infty$ ), it holds that

$$
\begin{aligned}
\frac{d U_{1}\left(\hat{e}_{1}, \hat{e}_{2}\right)}{d b_{2}} & =\frac{\partial U_{1}\left(e_{1}, e_{2}\right)}{\partial e_{1}} \frac{d e_{1}}{d b_{2}}+\frac{\partial U_{1}\left(e_{1}, e_{2}\right)}{\partial e_{2}} \frac{d e_{2}}{d b_{2}} \\
& =0+R_{e_{2}}^{1}\left(e_{1}, e_{2}\right) \frac{d e_{2}}{d b_{2}} \\
& >0 .
\end{aligned}
$$

As the first term is zero by the envelope theorem, the impact of agent 2's overconfidence on agent 1's payoff depends on the sign of the strategic effect which is positive. Hence, agent 1's expected payoff increases in agent 2's overconfidence.

Furthermore, the impact of $b_{2}$ on agent 2's own expected payoff is given by:

$$
\begin{aligned}
\frac{d U_{2}\left(\hat{e}_{1}, \hat{e}_{2}\right)}{d b_{2}} & =\frac{\partial U_{2}\left(e_{1}, e_{2}\right)}{\partial e_{1}} \frac{d e_{1}}{d b_{2}}+\frac{\partial U_{2}\left(e_{1}, e_{2}\right)}{\partial e_{2}} \frac{d e_{2}}{d b_{2}} \\
& =R_{e_{1}}^{2}\left(e_{1}, e_{2}\right) \frac{d e_{1}}{d b_{2}}+\left(R_{e_{2}}^{2}\left(e_{1}, e_{2}\right)-c^{\prime}\left(e_{2}\right)\right) \frac{d e_{2}}{d b_{2}} .
\end{aligned}
$$

rium behaviour but are not themselves part of the equilibrium in that they have to be correct. This is somewhat similar to models of level-k thinking used to analyse initial responses in normal form games (see, for example, Nagel, 1995; Costa-Gomes et al., 2001; or Crawford and Iriberri, 2007). In view of applications, such an implicit exclusion of the consistency condition regarding beliefs appears to be a justifiable simplification, for example, in settings where there are few opportunities for learning (e.g. due to a low frequency of repetition) or where the common restrictions of the agents' mental capacities are binding (e.g. due to time constraints or some other details of the job the agents have to carry out). 
The first term again reflects the strategic effect, which is positive as (1) efforts are strategic complements, i.e. $\frac{d e_{1}}{d e_{2}}>0$, by assumption and (2) agent 2's effort is increasing in his bias $b_{2}$, i.e. $\frac{d e_{2}}{d b_{2}}>0$, as the marginal return to effort is increasing in ability.

By contrast, the second term, which reflects the payoff effect of agent 2's mistaken belief about his own ability, is, of course, negative as the mistaken belief induces agent 2 to exert too much effort, i.e. $\hat{e}_{2}>\arg \max _{e_{2}} R^{2}\left(\hat{e}_{1}, e_{2}\right)-$ $c\left(e_{2}\right)$ which in turn implies $R_{e_{2}}^{2}\left(\hat{e}_{1}, \hat{e}_{2}\right)<c^{\prime}\left(\hat{e}_{2}\right)$.

Eventually, the overall effect on agent 2's expected payoff is determined by the trade-off between the strategic effect and the effect of agent 2's mistaken belief. In particular, if synergy effects are large, the strategic effect dominates and agent 2's payoff increases in $b_{2}$; this also holds if both synergy effects and agent 2's bias are small as a small bias results in a moderate increase in agent 2's effort and thus the mistaken belief effect is negligible. If synergies are small while the bias is comparably large, though, the overall effect on agent 2's utility is negative.

The overall effect of agent 2's overconfidence on agent 1's expected payoff, by contrast, depends only on the sign of the strategic effect which is positive. Accordingly, agent 1's payoff always increases in agent 2's overconfidence.

Summing up, both agents' efforts increase in $b_{2}$ if efforts are strategic complements and the marginal return to effort of agent 2 is increasing in $b_{2}-$ as assumed for the present discussion. Moreover, such an increase in efforts does not only lead to a higher team productivity (i.e. a higher firm value) and a higher expected payoff of agent 1 (which is increasing in $b_{2}$ ). It also increases the expected payoff of the overconfident agent 2 , provided that either synergies are large or, if they are small, also the bias itself $b_{2}$ is sufficiently small. Intuitively, the latter effect is due to the fact that agent 2 benefits from the positive externalities of the increased effort of agent 1. Even if these externalities are rather small, this effect outweighs the decrease in expected payoff resulting from agent 2's increased effort as long as the extent of overconfidence is moderate. Thus, we conclude: 
Lemma 1 Within the considered model of team production, being overconfident (and paired with a rational agent) increases the payoff of the overconfident agent if either synergy effects are sufficiently large or if both synergy effects and the agent's bias are small.

\section{Bias-Awareness}

In a next step, we turn to the discussion of teams which consist of two overconfident agents and address the question whether it is optimal for either agent to be informed or ignorant regarding the bias of his colleague. In doing so, we distinguish three settings: (Case 1) both agents are unaware of each other's biases; (Case 2) one agent is aware of the other's bias while the other agent is unaware of the colleague's bias; (Case 3) both agents are aware of each other's bias. As we will see, it is always better for agent 2 to be unaware of his colleague's overconfidence - irrespective of whether agent 1 is aware or unaware of agent 2's bias. The section concludes with some brief statements about the effect of partial awareness.

\section{Case 1: Both agents are unaware of each other's bias.}

If both agents are overconfident but unaware of their colleague's bias, each agent's decision situation is basically analogous to the situation of agent 2 considered in Section 3, i.e. the situation where an overconfident agent 2 is paired with a rational agent 1 . Thus, the derivation of the maximisation problems and equilibrium efforts for both agents is analogous to that for agent 2 in the previous section. ${ }^{9}$ Accordingly, agent 2's decision in the present setting is identical to the one discussed in Section 3:

$$
e_{2}^{00}=\hat{e}_{2} \cdot{ }^{10}
$$

\footnotetext{
${ }^{9}$ Since both agents are unaware of each other's bias, both believe that the colleague is unbiased. Moreover, each agent is unaware of the own bias. Thus, the agents' beliefs are effectively inconsistent with actual strategies (as they are unaware of the biases); see also footnote 8 . However, as soon as we deal with biased agents, consistency of beliefs is always an issue as biased agents, by definition, are at least unaware of their own bias.

${ }^{10}$ Here as below, the double digit in the exponent (" $00 "$ in this case) refers to the agents' awareness of biases: the first digit refers to agent 1 and the second to agent 2 ("0"
} 
Agent 1, in turn, now acts in the same way as agent 2; i.e. he also increases his effort compared to the individually rational level, $e_{1}^{*}$, because of his own overconfidence (but no longer, as he did before, because of - the knowledge of - his colleague's bias). Thus, agent 1's maximisation problem is given by:

$$
\max _{e_{1}} \widetilde{R}^{1}\left(e_{1}, e_{2} \mid b_{1}\right)-c\left(e_{1}\right)
$$

with corresponding FOC:

$$
\widetilde{R}_{e_{1}}^{1}\left(e_{1}, e_{2} \mid b_{1}\right)=c^{\prime}\left(e_{1}\right)
$$

and SOC:

$$
\widetilde{R}_{e_{1} e_{1}}^{1}\left(e_{1}, e_{2} \mid b_{1}\right)-c^{\prime \prime}\left(e_{1}\right)<0
$$

Denoting the resulting equilibrium effort by $e_{1}^{00}$, we obtain the following equilibrium payoffs based on actual abilities: ${ }^{11}$

$$
U_{1}^{00}:=U_{1}\left(e_{1}^{00}, e_{2}^{00}\right)=R^{1}\left(e_{1}^{00}, e_{2}^{00}\right)-c\left(e_{1}^{00}\right)
$$

and

$$
U_{2}^{00}:=U_{2}\left(e_{1}^{00}, e_{2}^{00}\right)=R^{2}\left(e_{1}^{00}, e_{2}^{00}\right)-c\left(e_{2}^{00}\right) .
$$

In order to determine the effect of an agent's bias on his own payoff, we have to consider the derivative of $U_{i}^{11}$ with respect to $b_{i}$ :

$$
\begin{aligned}
\frac{d U_{i}^{00}\left(e_{1}^{00}, e_{2}^{00}\right)}{d b_{i}} & =\frac{\partial U_{i}\left(e_{1}^{00}, e_{2}^{00}\right)}{\partial e_{i}} \frac{d e_{i}^{00}}{d b_{i}}+\frac{\partial U_{i}\left(e_{1}^{00}, e_{2}^{00}\right)}{\partial e_{-i}} \frac{d e_{-i}^{00}}{d b_{i}} \\
& =\left(R_{e_{i}}^{i}\left(e_{1}^{00}, e_{2}^{00}\right)-c^{\prime}\left(e_{i}^{00}\right)\right) \frac{d e_{i}^{00}}{d b_{i}}+R_{e_{-i}}^{i}\left(e_{1}^{00}, e_{2}^{00}\right) \frac{d e_{-i}^{00}}{d b_{i}}
\end{aligned}
$$

Note that the first term of this expression derives from agent $i$ 's mistaken belief and is negative as $\frac{d e_{i}}{d b_{i}}>0$ (recall that the marginal return to effort was assumed to increase in ability). Moreover, the strategic effect is zero as both indicating unawareness of the respective other agent's bias and "1" indicating awareness of it).

${ }^{11}$ Note that, as both agents are unaware of the other's bias, equilibrium efforts only depend on each agent's own bias. 
agents are unaware of the other's bias, i.e. $\frac{d e_{-i}}{d b_{i}}=0$. Thus, we conclude:

Lemma 2 Being overconfident reduces agent $i$ 's payoff if agent $-i$ is unaware of this bias.

\section{Case 2: One agent is aware, one unaware of the other's bias.}

Suppose agent 2 is aware of the bias of agent 1 but agent 1 is still unaware of his colleague's bias. ${ }^{12}$ Obviously, the maximisation problem and the corresponding equilibrium effort of agent 1 remain the same as in Case 1. Thus, we have: ${ }^{13}$

$$
e_{1}^{01}=e_{1}^{00}
$$

For agent 2, however, things are different. In particular, agent 2 now accounts for agent 1's overconfidence. Thus, as efforts are strategic complements, agent 2's effort increases in $b_{1}$ (because agent 1's marginal return to effort increases in $b_{1}$ ):

$$
\frac{d e_{2}^{01}}{d b_{1}}=\frac{d e_{2}^{01}}{d e_{1}^{01}} \frac{d e_{1}^{01}}{d b_{1}}=-\frac{\tilde{R}_{e_{1} b_{1}}^{1}\left(e_{1}^{01}, e_{2}^{01} \mid b_{1}\right)}{\tilde{R}_{e_{1} e_{1}}^{1}\left(e_{1}^{01}, e_{2}^{01} \mid b_{1}\right)-c^{\prime \prime}\left(e_{1}^{01}\right)} \frac{d e_{2}^{01}}{d e_{1}^{01}} .
$$

Note that there are now two reasons for agent 2 to increase his effort: (1) the biased perception of his own ability (which he is not aware of), and (2) the awareness of the colleague's overconfidence. Thus, agent 2's effort is not only higher than in the fully rational team, but also higher than his effort in the case where he is unaware of agent 1's bias, i.e.:

$$
e_{2}^{01}>e_{2}^{00}
$$

This implies that the team's productivity is increased compared to the fully rational team and the team with two overconfident agents who are both unaware of their colleague's bias. ${ }^{14}$

\footnotetext{
${ }^{12}$ Due to the symmetry of the problem, the case that agent 1 is aware of agent 2's bias follows immediately from interchanging the agents.

${ }^{13}$ Note that " 01 " in the exponent now indicates that agent 1 is unaware of agent 2's bias while agent 2 is aware of agent 1's bias.

${ }^{14}$ It can also be shown that the team's productivity increases compared to the team with only one overconfident agent.
} 
Moreover, the corresponding equilibrium payoffs of the agents in this case are as follows:

$$
U_{1}^{01}:=U_{1}\left(e_{1}^{01}, e_{2}^{01}\right)=U_{1}\left(e_{1}^{00}, e_{2}^{01}\right)=R^{1}\left(e_{1}^{00}, e_{2}^{01}\right)-c\left(e_{1}^{00}\right)
$$

and

$$
U_{2}^{01}:=U_{2}\left(e_{1}^{01}, e_{2}^{01}\right)=U_{2}\left(e_{1}^{00}, e_{2}^{01}\right)=R^{2}\left(e_{1}^{00}, e_{2}^{01}\right)-c\left(e_{2}^{01}\right)
$$

Payoff comparison when one agent is unaware of the colleague's bias.

A simple payoff comparison yields that if one agent, say agent 1, is unaware of agent 2's bias, agent 2 is better off being unaware of the bias of agent 1 :

$$
U_{2}^{00}>U_{2}^{01} \Leftrightarrow R^{2}\left(e_{1}^{00}, e_{2}^{00}\right)-c\left(e_{2}^{00}\right)>R^{2}\left(e_{1}^{00}, e_{2}^{01}\right)-c\left(e_{2}^{01}\right),
$$

as $R^{2}\left(e_{1}, e_{2}\right)-c\left(e_{2}\right)$ is concave and $e_{2}^{01}>e_{2}^{00}>\arg \max _{e_{2}} R^{2}\left(e_{1}^{00}, e_{2}\right)-c\left(e_{2}\right)$.

Intuitively, accounting for agent 1's overconfidence induces agent 2 to further increase his effort in an attempt to exploit effort complementarities. Yet, his effort is already above the individual optimum - because of his own overconfidence - and the further increase in effort is not complemented by agent 1 . Thus, we conclude:

Lemma 3 If both agents are overconfident and agent 1 is unaware of the bias of agent 2, then agent 2, ceteris paribus, is better off if he is also unaware of agent 1's bias than if he were aware of it.

\section{Case 3: Both agents are aware of each other's bias.}

The situation in which both agents are aware of each other's bias is analogous to the situation of agent 2 in Case 2 where agent 2 is aware of agent 1's bias; i.e. the equilibrium effort level of agent 2 is given by:

$$
e_{2}^{11}=e_{2}^{01}
$$

However, for agent 1 , who now takes into account the bias of agent 2 , the 
equilibrium effort level is increased compared to Case 2:

$$
e_{1}^{11}>e_{1}^{01}
$$

as efforts are strategic complements and agent 2's marginal return to effort is increasing in his bias. Note that under these conditions both agents increase their effort for two reasons: (1) their own overconfidence and (2) their attempt to complement their colleague's increased effort.

Accordingly, the agents' resulting equilibrium payoffs in this case are given by:

$$
U_{1}^{11}:=U_{1}\left(e_{1}^{11}, e_{2}^{11}\right)=U_{1}\left(e_{1}^{11}, e_{2}^{01}\right)=R^{1}\left(e_{1}^{11}, e_{2}^{01}\right)-c\left(e_{1}^{11}\right)
$$

and

$$
U_{2}^{11}:=U_{2}\left(e_{1}^{11}, e_{2}^{11}\right)=U_{2}\left(e_{1}^{11}, e_{2}^{01}\right)=R^{2}\left(e_{1}^{11}, e_{2}^{01}\right)-c\left(e_{2}^{01}\right)
$$

Payoff comparison when one agent is aware of the colleague's bias.

Next, we consider agent 2 and compare his payoff for the case where he is aware of agent 1's bias with the case where he is not - assuming that agent 1 is aware of agent 2's bias. A comparison of agent 2's payoff in both instances shows that being unaware of agent 1's bias is preferable for agent 2 if the following holds: ${ }^{15}$

$$
U_{2}^{10}>U_{2}^{11} \Leftrightarrow R^{2}\left(e_{1}^{11}, e_{2}^{00}\right)-c\left(e_{2}^{00}\right)>R^{2}\left(e_{1}^{11}, e_{2}^{01}\right)-c\left(e_{2}^{01}\right),
$$

as $R^{2}\left(e_{1}, e_{2}\right)-c\left(e_{2}\right)$ is concave and $e_{2}^{01}>e_{2}^{00}>\arg \max _{e_{2}} R^{2}\left(e_{1}, e_{2}\right)-c\left(e_{2}\right){ }^{16}$

The intuition for this result is the same as before: Complementing agent 1 's additional effort is detrimental for agent 2 because agent 2's effort is

\footnotetext{
${ }^{15}$ Recall that the "01" in the exponent refers to the case where both agents are overconfident but only agent 1 is aware of the bias of agent 2 , which is analogous to Case 2 except that the information structure is reversed. Note further that $e_{2}^{10}=e_{2}^{00}$ and $e_{1}^{10}=e_{1}^{11}$.

${ }^{16}$ Irrespective of whether agent 2 is aware or unaware of agent 1's bias, it is obviously better for agent 2 if agent 1 is aware of agent 2's bias, than if he is not, i.e. $U_{2}^{11}>U_{2}^{01}$ $\Leftrightarrow R^{2}\left(e_{1}^{11}, e_{2}^{01}\right)-c\left(e_{2}^{01}\right)>R^{2}\left(e_{1}^{01}, e_{2}^{01}\right)-c\left(e_{2}^{01}\right)$ as $e_{1}^{11}>e_{1}^{01}$ and $U_{2}^{10}>U_{2}^{00} \Leftrightarrow R^{2}\left(e_{1}^{11}, e_{2}^{00}\right)-$ $c\left(e_{2}^{00}\right)>R^{2}\left(e_{1}^{00}, e_{2}^{00}\right)-c\left(e_{2}^{00}\right)$ as $e_{1}^{11}=e_{1}^{10}>e_{1}^{00}$.
} 
already above the optimum - due to his own bias - and because the further increase is not complemented by agent 1 . Similar to the previous situation, we thus conclude:

Lemma 4 If both agents are overconfident and agent 1 is aware of the bias of agent 2, then agent 2, ceteris paribus, is better off if he is unaware of agent 1 's bias.

\section{Consequences of Partial Awareness.}

Finally, we want to briefly comment on the effects of partial awareness of biases; see Appendix A for a formal discussion. For the sake of argument, we assume that an agent who is "partially aware" of his colleague's overconfidence assigns probability $p \in[0,1]$ to the case that his colleague has bias $b_{i}>0$, where $b_{i}$ is the true bias of agent $i .{ }^{17}$ As it turns out, partial awareness essentially reduces the strength of the effects discussed above while keeping the direction of changes. In particular, it holds (see Appendix A for a formal derivation):

Lemma 5 An agent is best off being unaware of the colleague's bias; and being partially aware is better than being fully aware. Moreover, for an overconfident agent it is optimal if his colleague is fully aware of the bias; and partial awareness is better than unawareness.

\section{Comparison with Rational Team}

In the previous sections, we have shown that within the proposed model of team production (1) overconfidence can be beneficial for the biased agent and (2) if an agent is overconfident, it is always best for him to be unaware of a potential bias of his colleague. In view of a general comparison between rational and overconfident agents, however, it is also interesting to ask how individual payoffs in a team of two overconfident agents compare to those in

\footnotetext{
${ }^{17}$ It is straightforward to generalize our analysis to more general cases of "partial awareness", where an agent attaches different probabilities to different sizes of the bias.
} 
a fully rational team. In the remainder of this section, we show that, under fairly weak conditions, individual payoffs in a team of two overconfident agents are higher than in a team of two rational agents.

Consider a situation in which both agents are overconfident but unaware of their colleague's bias, i.e. a situation where overconfidence is present in its "individually optimal" form (i.e. when combined with unawareness of the colleague's bias). Thus, both agents' overconfidence is not complemented by an increased effort of the respective colleague through awareness of biases.

In order to obtain a clear picture for the comparison of individual payoffs for this scenario let us first consider the case in which one agent, agent $i$, is biased and the other agent exerts his benchmark equilibrium effort $e_{-i}^{*}$ (e.g. because he is rational but unaware of his colleague's bias). For this case, the following holds:

$$
R^{i}\left(e_{i}^{00}, e_{-i}^{*}\right)-c\left(e_{i}^{00}\right)<R^{i}\left(e_{i}^{*}, e_{-i}^{*}\right)-c\left(e_{i}^{*}\right),
$$

as $R^{i}$ is concave and $e_{i}^{00}>e_{i}^{*}=\arg \max _{e_{i}} R^{i}\left(e_{i}, e_{-i}^{*}\right)-c\left(e_{i}\right)$. However, we already know from the previous discussion that $e_{-i}^{00}>e_{-i}^{*}$ and that being biased is beneficial if the own increased effort is complemented by an increase in the effort of the colleague (who knows about the bias and wants to exploit synergy effects). But, of course, an increased effort of agent $-i$, which results from agent $-i$ 's own bias, can increase the payoff of agent $i$ in essentially the same way as an increase in agent -i's effort resulting from an attempt to optimally exploit synergy effects (provided that the synergy effects are sufficiently large). In this case, we have:

$$
R^{i}\left(e_{i}^{00}, e_{-i}^{00}\right)-c\left(e_{i}^{00}\right)>R^{i}\left(e_{i}^{*}, e_{-i}^{*}\right)-c\left(e_{i}^{*}\right),
$$

In fact, the comparison remains positive also for small synergy effects if biases are moderate. Intuitively, this holds as a small bias of agent $i$ induces only a moderate increase in agent $i$ 's own effort. Hence, a smaller "synergetic feedback" through agent $-i$ 's effort is required to "reimburse" the biased agent $i$. 
Summing up, the above result in favour of overconfidence is rather intuitive as we have already seen that individual payoffs for a biased agent in a team of one overconfident and one rational agent are increased (cf. Section $3)$. The maximisation problem of the overconfident agent, say agent 2 , is the same in both the team with one and the team with two overconfident agents: He is biased himself (and unaware of his bias) and thinks his colleague, agent 1 , is unbiased and, hence, will exert the same effort in both cases. Moreover, if the additional effort exerted by a rational agent 1 in order to complement agent 2's additional effort (due to agent 2's overconfidence) is enough to overcompensate agent 2 for his increased effort cost, then it is natural to expect that an overconfidence bias of agent 1 has a similar effect. Eventually, both the awareness of agent 2's bias (of the rational agent 1) and the own overconfidence of agent 1 have a similar effort enhancing effect; and the increased effort of agent 1 (due to his overconfidence) is what compensates agent 2 for his additional cost.

Finally, it is interesting to note that the favourable comparison of individual payoffs in an overconfident team with those in a fully rational team does not depend on the overconfident agents' unawareness of their colleague's bias. In fact, even if one or both agents are (partially) aware of their colleague's bias, individual payoffs are higher than those in a fully rational team if either synergy effects are comparably large, or if synergy effects are small and biases are moderate; see Appendix B for a more detailed argument.

Proposition 1 below qualitatively summarises the main points of the preceding discussion.

Proposition 1 For the above model of team production with synergy effects, the following results hold:

1. Individual payoffs in a team of one overconfident and one rational agent are higher than those in a team with two rational agents - provided that the rational agent is aware of his colleague's bias and either synergy effects are sufficiently large, or synergy effects are small and the bias is moderate. 
2. The individual payoff of an overconfident agent whose colleague is also overconfident is always higher if he is not aware of his colleague's bias (irrespective of whether the colleague is aware of the other agent's bias).

3. Individual payoffs in a team of two overconfident agents which are both unaware of the other's bias are higher than those in a team of two rational agents - provided that either synergy effects are sufficiently large, or synergy effects are small and biases are moderate. ${ }^{18}$

\section{Concluding Remarks}

In this paper, we have considered an intuitive model of team production with effort complementarities in order to emphasise the potentially positive effects of being overconfident. As we have shown, a more rational perspective on others, i.e. awareness of the overconfidence of others, is suboptimal for an agent who is overconfident himself. More specifically, within the considered model of team production, the payoff of an overconfident agent, whose colleague is also overconfident, is always higher if he is unaware of his colleague's bias. Thus, although the empirical evidence on the matter is scarce, our results provide a possible rationale for why many people appear to be unaware of the overconfidence biases of others (cf. Ludwig and Nafziger, 2011).

Moreover, we have shown that individual payoffs in both a team of a rational and an overconfident agent as well as in a team of two overconfident agents are higher than in a team with two rational agents whenever either synergy effects are sufficiently large or biases are moderate. Thus, the present analysis gives further support to the notion that being overconfident is beneficial not only in view of aggregate outcomes (as overconfidence seems to enhance effort and therefore team productivity) but also for the overconfident individuals themselves. In fact, the analysis also suggests that overconfident agents have no incentive to gather information about a colleague's poten-

\footnotetext{
${ }^{18}$ Here we consider only the case in which information about biases is optimal, i.e. biased agents are unaware of the biases of others. Similar results hold if one or both agents are (partially) aware of the bias of their colleague, albeit with slightly stricter restrictions on synergy effects and the size of the biases.
} 
tially biased self-perception (even if such information was costless). Thus, our results provide a possible rationale for why overconfidence may indeed be (and remain) as widespread a phenomenon as empirical and experimental research indicates.

\section{Appendix}

\section{A. Partial Awareness}

In order to model a situation in which agent $i$ is uncertain of his colleague's bias, we assume that agent $i$ assigns probability $p \in[0,1]$ to the case that his colleague $-i$ has bias $b_{-i}>0$. For the sake of argument, suppose $i=1$. Thus, agent 1 believes that with probability $p$ agent 2 follows equilibrium strategy $\tilde{e}_{2}$ (where the tilde denotes that agent 2 is biased) and with probability $1-p$ strategy $e_{2}$. Accordingly, agent 1 has to solve the following maximisation problem:

$$
\max _{e_{1}} p \cdot \tilde{R}^{1}\left(e_{1}, \tilde{e}_{2} \mid b_{1}\right)+(1-p) \cdot \tilde{R}^{1}\left(e_{1}, e_{2} \mid b_{1}\right)-c\left(e_{1}\right)
$$

with FOC:

$$
p \cdot \tilde{R}_{e_{1}}^{1}\left(e_{1}, \tilde{e}_{2} \mid b_{1}\right)+(1-p) \cdot \tilde{R}_{e_{1}}^{1}\left(e_{1}, e_{2} \mid b_{1}\right)=c^{\prime}\left(e_{1}\right) .
$$

Since (by assumption) an agent's effort rises in his ability and, hence, in his bias, i.e. $\frac{d e_{2}}{d b_{2}}>0$, we have $\tilde{e}_{2}>e_{2}$. Moreover, as efforts are strategic complements, it follows:

$$
\tilde{R}_{e_{1}}^{1}\left(e_{1}, \tilde{e}_{2} \mid b_{1}\right)>\tilde{R}_{e_{1}}^{1}\left(e_{1}, e_{2} \mid b_{1}\right)
$$

Hence, the left hand side of the FOC must be increasing in $p$. For $p=1$, agent 1 attaches probability one to the case that agent 2 has bias $b_{2}$ (which corresponds to the case that agent 1 is completely aware of agent 2 's bias). 
In this case, the FOC becomes:

$$
\tilde{R}_{e_{1}}^{1}\left(e_{1}, \tilde{e}_{2} \mid b_{1}\right)=c\left(e_{1}\right)
$$

Obviously, the left hand side of this FOC is larger than if agent 1 is aware of agent 2's bias. Hence, also the right hand side must be larger.

As $c^{\prime \prime}>0$, by assumption, agent 1 exerts a higher effort if he is aware of agent 2's bias than if he is partially aware of it - irrespective of whether agent 2 is (partially) aware or unaware of agent 1's bias. Thus, we have $e_{1}^{p k} \leq e_{1}^{1 k}$ (with equality if $p=1$ ), where the exponent $p$ indicates that agent 1 is partially aware of agent 2's bias, and $k \in[0,1]$ indicates that agent 2 is unaware / partially aware / aware of agent 1's bias $b_{1}>0$. Moreover, an analogous argument shows that agent 1's effort in case he is partially aware is larger than his effort in case he is unaware of agent 2's bias, i.e. $e_{1}^{p k} \geq e_{1}^{0 k}$ (with equality if $p=0$ ). Thus, taken together, we have

$$
e_{1}^{1 k} \geq e_{1}^{p k} \geq e_{1}^{0 k}
$$

Note that agent 2's effort does not depend on agent 1's awareness of agent 2's bias but only on agent 2's awareness of his colleague's bias (see also the discussion of Case 1-3 in Section 4):

$$
e_{2}^{1 k}=e_{2}^{p k}=e_{2}^{0 k}
$$

Next, we compare agent 1's equilibrium payoffs depending on whether he is (partially) aware or unaware of agent 2's bias. In order to do so, we denote his equilibrium payoff by $R^{1}\left(e_{1}^{x k}, e_{2}^{x k}\right)-c\left(e_{1}^{x k}\right)$, where $x, k \in[0,1]$, and $x$ denotes agent 1's awareness status of agent 2's bias. - Recall that agent 1 is biased himself so that his effort is higher than optimal irrespective of his awareness status regarding agent 2's bias. - As $R^{1}\left(e_{1}, e_{2}\right)-c\left(e_{1}\right)$ is concave in $e_{1}$ and $e_{1}^{1 k} \geq e_{1}^{p k} \geq e_{1}^{0 k}$, we have

$$
R^{1}\left(e_{1}^{1 k}, e_{2}^{p k}\right)-c\left(e_{1}^{1 k}\right) \leq R^{1}\left(e_{1}^{p k}, e_{2}^{p k}\right)-c\left(e_{1}^{p k}\right) \leq R^{1}\left(e_{1}^{0 k}, e_{2}^{p k}\right)-c\left(e_{1}^{0 k}\right) .
$$


Thus, we conclude

Lemma A.1 An agent is best off being unaware of the colleague's bias; and being partially aware is better than being fully aware.

For agent 2 it also holds that his effort is higher if he is partially aware than if he is unaware and highest if he is aware of agent 1's bias - irrespective of agent 1's awareness status $x \in[0,1]$, i.e. $e_{2}^{x 1} \geq e_{2}^{x p} \geq e_{2}^{x 0}$. Since agent 1 's effort does not vary with his colleague's awareness status, i.e. $e_{1}^{x 1}=e_{1}^{x p}=e_{1}^{x 0}$, we have

$$
R^{1}\left(e_{1}^{x 1}, e_{2}^{x 1}\right)-c\left(e_{1}^{x 1}\right) \geq R^{1}\left(e_{1}^{x p}, e_{2}^{x p}\right)-c\left(e_{1}^{x p}\right) \geq R^{1}\left(e_{1}^{x 0}, e_{2}^{x 0}\right)-c\left(e_{1}^{x 0}\right)
$$

Thus, we conclude

Lemma A.2 An overconfident agent is best off if the colleague is aware of the bias; and partial awareness is better than unawareness.

\section{B. Comparison: 2 Overconfident vs. 2 Rational Agents Both overconfident agents are aware of their colleague's bias.}

If both agents are overconfident and aware of their colleague's bias, we have:

$$
R^{i}\left(e_{i}^{11}, e_{-i}^{*}\right)-c\left(e_{i}^{11}\right)<R^{i}\left(e_{i}^{*}, e_{-i}^{*}\right)-c\left(e_{i}^{*}\right)
$$

as $R^{i}$ is concave and $e_{i}^{11}>e_{i}^{*}=\arg \max _{e_{i}} R^{i}\left(e_{i}, e_{-i}^{*}\right)-c\left(e_{i}\right)$. Yet, as $e_{-i}^{11}>e_{-i}^{*}$, it holds that:

$$
R^{i}\left(e_{i}^{11}, e_{-i}^{11}\right)-c\left(e_{i}^{11}\right)>R^{i}\left(e_{i}^{*}, e_{-i}^{*}\right)-c\left(e_{i}^{*}\right),
$$

provided that synergy effects are sufficiently large. And this also holds if biases are moderate (as a small bias results in a moderate increase of effort and therefore a smaller "synergetic feedback" through agent $-i$ 's effort is required). 


\section{Only one overconfident agent is aware of his colleague's bias.}

Similar to the above argument individual payoffs again are higher than for a fully rational team if synergy effects are sufficiently large or biases are moderate:

$$
R^{i}\left(e_{i}^{01}, e_{-i}^{01}\right)-c\left(e_{i}^{01}\right)>R^{i}\left(e_{i}^{*}, e_{-i}^{*}\right)-c\left(e_{i}^{*}\right),
$$

with $e_{i}^{01}>e_{i}^{*}$ and $e_{-i}^{01}>e_{-i}^{*}$ and, hence, $U_{i}^{01}>U_{i}^{*}$. The argument is analogous to the one before.

\section{References}

Aghion, P. and J. Tirole (1994), "The Management of Innovation," Quarterly Journal of Economics, 109, 11851209.

Alchian, A.A. and H. Demsetz (1972), "Production, Information Costs, and Economic Organization," American Economic Review, 62, 777-795.

Alchian, A.A. and S.E. Woodward (1987), "Reflections on the Theory of the Firm," Journal of Institutional and Theoretical Economics, 143, 110136 .

Alicke, M.D. and O. Govorun (2005), "The Better-Than-Average Effect," The Self in Social Judgment, Psychology Press, Philadelphia, 83-106.

Costa-Gomes, M., Crawford, V. and B. Broseta (2001), "Cognition and Behavior in Normal-Form Games: An Experimental Study," Econometrica 69, 11931235.

Crawford, V. and N. Iriberri, (2007), "Fatal Attraction: Salience, Naivity, and Sophistication in Experimental Hide and Seek Games.," American Economic Review 97, 17311770.

De la Rosa, L. (2007), "Overconfidence and Moral Hazard," Danish Centre for Accounting and Finance, Working Paper No 24. 
Felson, R.B. (1984), "The Effects of Self-Appraisals of Ability on Academic Performance," Journal of Personality and Social Psychology, 47, 944952.

Gervais, S. and I. Goldstein (2007), "The Positive Effects of Biased SelfPerceptions in Firms," Review of Finance, 11, 453-496.

Gigerenzer, G., U. Hoffrage and H. Kleinbolting (1991), "Probabilistic Mental Models: A Brunswikian Theory of Confidence," Psychological Review, 98, 506-528.

Griffin, D. and A. Tversky (1992), "The Weighing of Evidence and the Determinants of Confidence," Cognitive Psychology, 24, 411-435.

Grinblatt, M., and M. Keloharju (2009), "Sensation Seeking, Overconfidence, and Trading Activity," Journal of Finance, 64, 549-578.

Grossman, S. J. and O.D. Hart (1986), "The Costs and Benefits of Ownership: A Theory of Vertical and Lateral Integration," Journal of Political Economy, 94, 691719.

Heath, C., R.P. Larrick, and G. Wu (1999), "Goals as Reference Points," Cognitive Psychology, 38, 79-109.

Heaton, J.B. (2002), "Managerial Optimism and Corporate Finance," Financial Management, 31, 33-45.

Hirshleifer, D. and G.Y. Luo (2001), "On the Survival of Overconfident Traders in a Competitive Securities Market," Journal of Financial Markets, 4, 73-84.

Holmström, B. and J. Roberts (1998), "The Boundaries of the Firm Revisited," Journal of Economic Perspectives, 12, 7394.

Hvide, H. K. (2002), "Pragmatic Beliefs and Overconfidence," Journal of Economic Behavior and Organization, 48, 15-28. 
Jensen, M. C. and W.H. Meckling (1995), "Specific and General Knowledge and Organizational Structure," Journal of Applied Corporate Finance, $8,418$.

Juslin, P. (1994), "The Overconfidence Phenomenon as a Consequence of Informal Experimenter-Guided Selection of Almanac Items," Organizational Behavior and Human Decision Processes, 57, 226-246.

Kahnemann D. and A. Tversky (1996), "On the Reality of Cognitive Illusions: A Reply to Gigerenzer's Critique," Psychological Review, 103, 582-591.

Koehler, D.J., L. Brenner and D. Griffin (2002), "The Calibration of Expert Judgment: Heuristics and Biases Beyond the Laboratory," in: Gilovich, T., D. Griffin and D. Kahnemann (eds.), Heuristics and Biases: The Psychology of Intuitive Judgment, Cambridge University Press, Cambridge.

Kyle, A.S. and F.A. Wang (1997), "Speculation Duopoly with Agreement to Disagree: Can Overconfidence Survive the Market Test?," Journal of Finance, 52, 2073-2090.

Langer, E. J. (1975), "The Illusion of Control," Journal of Personality and Social Psychology, 32(2), 311-328.

Larwood, L. and W. Whittaker (1977), "Managerial Myopia: Self-Serving Biases in Organizational Planning," Journal of Applied Psychology, 62, 194-198.

Locke, E.A. and G.P. Latham (1990), A Theory of Goal Setting and Task Performance, Englewood Cliffs, N.J.

Ludwig, S. and J. Nafziger (2011), "Beliefs About Overconfidence," Theory and Decision, 70, 475-500.

Malmendier, U. and G. Tate (2005), "CEO Overconfidence and Corporate Investment," Journal of Finance, 60, 2661-2700. 
Malmendier, U. and G. Tate (2008), "Who Makes Acquisitions? CEO Overconfidence and the Market's Reaction," Journal of Financial Economics, 89, 20-43.

Moore, D.A. and P.J. Healy (2008), "The Trouble with Overconfidence," Psychology Review, 115, 502-517.

Morris, S. (1996), "Speculative Investor Behavior and Learning," Quarterly Journal of Economics, 111, 1111-1133.

Nagel, R. (1995), "Unravelling in Guessing Games: An Experimental Study," American Economic Review 85, 13131326.

Santos-Pinto, L. (2008), "Positive Self-Image and Incentives in Organizations," Economic Journal, 118, 1315-1332.

Skata, D. (2008), "Overconfidence in Psychology and Finance - an Interdisciplinary Literature Review," Bank i Kredyt, 4, 33-50.

Squintani (2006), "Equilibrium and Mistaken Self-Perception," Economic Theory, 27, 615-641.

Svenson, O. (1981), "Are We All Less Risky and More Skillful than Our Fellow Drivers?," Acta Psychologica, 47, 143-148.

Taylor, S.E. and J.D. Brown (1988), "Illusion and Well-Being: A Social Psychological Perspective on Mental Health," Psychological Bulletin, 103, 193-210.

Weinstein, N.D. (1980), "Unrealistic Optimism about Future Life Events," Journal of Personality and Social Psychology, 39, 806-820.

Zhang, Y. and A. Fishbach (2010), "Counteracting Obstacles with Optimistic Predictions," Journal of Experimental Psychology: General, 139, 16-31. 